\title{
Negocios Internacionales en la nueva normalidad
}

Javier Gustavo Oyarse CRUz

Abogado por la Universidad de San Martín de Porres. Máster en Derecho Civil y Comercial por la Universidad de San Martín de Porres. Máster en International Business por la Universidad Rey Juan Carlos. Doctor en Educación por la Universidad de San Martín de Porres. Profesor en Escuela de Posgrado de la Universidad Nacional Mayor de San Marcos, Pontificia Universidad Católica del Perú, Universidad de San Martin de Porres y de la Universidad

Peruana de Ciencias Aplicadas.

SUMARIO:

I. Introducción.

II. Negocios Internacionales.

III. Derecho Aduanero.

IV. Gestión de Negocios Internacionales de manera virtual.

V. Oportunidades de Mejora.

VI. Conclusiones. 


\title{
RESUMEN:
}

El autor a través de este artículo pretende analizar si el Perú se encuentra preparado para continuar con los negocios internacionales en la nueva normalidad causada por el nuevo coronavirus. Asimismo, demuestra que se ha logrado la digitalización de los servicios aduaneros, tanto en el sector público como en el sector privado, de modo que existen mayores herramientas virtuales.

Palabras clave: Negocios Internacionales, coronavirus, virtual, digital, Derecho Aduanero, comercio exterior.

\begin{abstract}
:
Throughout this article, the author intends to analyze whether Peru is prepared to continue with international business in the new normalcy caused by the new coronavirus. It also shows that the digitization of custom services has been achieved, both in the public and private sectors, so that more virtual tools exist.

Keywords: International Business, coronavirus, virtual, digital, Customs Law, foreign trade.
\end{abstract}

\section{INTRODUCCIÓN}

El año 2020 para muchos fue considerado como un año atípico, donde primaron las restricciones sanitarias que obligan al distanciamiento social, repercutiendo en las actividades de comercio, industria, educación; así como las actividades sociales, culturales, deportivas, entre otras. Quizás podemos coincidir en que se trata de un año en que cualquier planificación empresarial estará sujeta a cambios constantes.

En este escenario de gran incertidumbre, surgen algunas voces respecto a que el virus que produce la COVID-19 estaría mutando, y la carrera contra el tiempo que vienen desarrollando los grandes laboratorios por encontrar una vacuna podrían resultar improductivos, en la medida que se requiere un mayor tiempo de estudios y experimentación para estar seguros de su eficacia.

Otros señalan con cierto pesimismo que lo experimentado en el 2020 no es más que el preámbulo de futuras pandemias, que vendrán teniendo mayor peligrosidad y agresividad para los habitantes de nuestro planeta. Por lo que nos preguntamos, eestamos realmente preparados para continuar realizando negocios internacionales en esa nueva normalidad?

En las siguientes líneas permítannos responder esta interrogante, relevando la singular importancia de las operaciones de comercio interna- cional para el abastecimiento de los mercados y la ansiada reactivación económica. Lo haremos revisando algunas iniciativas que surgieron para superar las restricciones que genera la cuarentena al momento de gestionar las actividades de comercio exterior.

\section{NEGOCIOS INTERNACIONALES}

En Latinoamérica, los gobernantes decidieron adoptar medidas de confinamiento a partir de marzo 2020, paralizando diversas actividades como la educación, las industrias, y el comercio en general, que estuvo sujeto a varias restricciones; lo cual se entiende si tomamos en cuenta que el contagio masivo del coronavirus pone en peligro la vida de los pacientes infectados debido a la limitada capacidad de respuesta de los nosocomios en nuestro país.

Pero en este escenario de caos y desconcierto, cabe mencionar los riesgos latentes que provenían de compromisos o contratos firmados desde el año 2019 que comprometían a importadores y exportadores desde el Perú a realizar la nacionalización de bienes y/o gestionar embarques de mercancías durante el año 2020, bajo penalidades previstas en los respectivos contratos.

Por esa razón, fue necesario destrabar las restricciones al comercio internacional que los gobernantes habían impuesto por temor al contagio, flexibilizando las medidas para 
la recepción de naves en los puertos, y del mismo modo, creando protocolos para la recepción de aeronaves en los aeropuertos. ${ }^{1}$ Es decir, no era prudente cerrar los mercados, porque agravaría aún más la crisis sanitaria. La Administración Aduanera se vio golpeada duramente con el incremento de los fletes, que complicó un poco más esta tarea de reactivar las actividades vinculadas a los negocios internacionales.

Como deben suponer, estas medidas se plasman en normas que son emitidas por algunas entidades públicas con el firme propósito de lograr conectarse de manera competitiva con el mercado global de bienes y servicios. Normas que provienen de los diferentes sectores involucrados con los negocios internacionales, como por ejemplo el Ministerio de Transportes y Comunicaciones, el Ministerio de Salud, el Ministerio de Trabajo y Promoción del Empleo, Ministerio de Economía y Finanzas, etc.

\section{DERECHO ADUANERO}

Las normas a las que hacemos referencia en el acápite anterior regulan las actividades vinculadas a los negocios internacionales, y pertenecen al ámbito del Derecho Aduanero, como disciplina perteneciente a las ciencias jurídicas que se encarga de regular el ingreso, salida y traslado de mercancías, medios de transporte y personas por las fronteras de cada país. Se trata de una disciplina jurídica autónoma ${ }^{2}$ que durante esta pandemia ha tenido que resolver sobre la marcha diversas situaciones que afectaban el comercio exterior.

El jurista mexicano Andrés Rohde ${ }^{3}$, respecto a la autonomía del derecho aduanero señala como fundamento que se trata de tres tipos, entre las cuales destaca la científica o dogmática, la didáctica y la legislativa. Así tenemos que desde el punto de vista dogmático existen algunas instituciones jurídicas que son de naturaleza global, como por ejemplo el control aduanero, que desde nuestra modesta opinión forma parte de la identidad propia de la Administración Aduanera en el mundo.

En cuanto a la autonomía didáctica, podemos mencionar que algunas Escuelas de Posgrado de universidades públicas y privadas en el Perú ya tienen incorporado dentro de su malla curricular un curso de especialización, estudio, investigación y actualización en materia de Derecho Aduanero y Comercio Exterior. No es difícil presagiar que en el futuro inmediato, algunos estudiantes elegirán como tema de investigación para su tesis los efectos de la pandemia en los negocios internacionales, la gestión aduanera y el comercio exterior peruano.

Y en lo que respecta a la autonomía legislativa, partimos de la Constitución Política del Perú que consagra las libertades de comercio, las mismas que luego sirven de fundamento a la Ley General de Aduanas, Ley de Delitos Aduaneros y sus Reglamentos. De manera concordante tenemos que cumplir con los Acuerdos Comerciales que nos vinculan con países amigos, considerados como socios comerciales para eliminar las barreras arancelarias y para arancelarias dentro de los procesos de integración económica que el Perú viene desarrollando con singular acierto.

El Derecho Aduanero como disciplina jurídica se encuentra en constante cambio, no sólo por los avances de la ciencia y la tecnología que

1. Resolución de Presidencia de Directorio No 0007-2020-APN-PD que aprueba los Lineamientos obligatorios para desarrollar procedimientos y protocolos para prevenir el contagio del COVID-19 en las instalaciones portuarias.

2. La autonomía del Derecho Aduanero es sostenida en Europa por Francisco Pelecha Sosaya (2009), Fernando Muñoz García (1974); en América es defendida por Ariosto D. Gonzales (1983), Manuel Gonzales Carrizales (1990), German Pardo (2009), Máximo Carvajal (2007); Ricardo Xavier Basaldúa (1992), Andrés Rhode (2202) y Héctor Vidal Albarracín (2004); entre otros.

3. Andrés Rohde Ponce, Derecho Aduanero Mexicano (Ciudad de México: Ediciones Fiscales ISEF, 2002). 
nos enfrentan a un entorno globalizado y competitivo de los negocios internacionales, sino fundamentalmente por los retos que surgen a raíz de la pandemia. Así podemos observar que varios procedimientos aduaneros se están adecuando progresivamente a plataformas digitales, con el objetivo de simplificar los trámites y ahorrar costos logísticos.

\section{GESTIÓN DE NEGOCIOS INTERNACIONA- LES DE MANERA VIRTUAL}

En la parte introductoria del presente artículo nos planteamos la siguiente pregunta: iestamos realmente preparados para continuar realizando negocios internacionales en esa nueva normalidad? Responder esta interrogante nos conduce a revisar algunos cambios que se produjeron desde marzo 2020 en adelante.

Tenemos por ejemplo que, siendo necesario evitar el contagio de los usuarios aduaneros, los diversos organismos del Estado Peruano pusieron al servicio de los administrados una Mesa de Partes Virtual para que se puedan gestionar los regímenes y servicios aduaneros de manera remota. ${ }^{4}$ Esta herramienta digital se viene utilizando para presentar solicitudes de clasificación arancelaria de mercancías, solicitudes de devolución por pagos indebidos o en exceso derivados de obligaciones tributaria aduaneras, solicitudes de fraccionamiento o aplazamiento de deudas aduaneras, etc.

Otro cambio importante fue la digitalización de los regímenes aduaneros de exportación e importación, cuyo objetivo fundamental consiste en eliminar el uso de documentos impresos en hojas de papel, simplificar trámites administrativos y brindar mayor transparencia en las gestiones aduaneras. Sin duda, este fue el cambio más relevante, dado que se trata de la implementación de un nuevo modelo de despacho aduanero basado en la declaración anticipada de las mercancías.

También destaca el rol del Ministerio de Comercio Exterior y Turismo para promover las exportaciones, lo cual se evidencia con la aprobación del reglamento para actualizar la Ventanilla Única de Comercio Exterior VUCE ${ }^{5}$, que permite obtener de manera digital los permisos y autorizaciones para mercancías restringidas, y también el certificado de origen para las transacciones comerciales realizadas entre los países miembros de la Alianza del Pacífico.

Otro cambio importante, fue la aprobación del Reglamento del Exportador Autorizado ${ }^{6}$, que se convierte en un eficaz mecanismo que evidencia la confianza en los exportadores, para delegarles la responsabilidad de certificar el origen de sus propias mercancías, previo cumplimiento de algunos requisitos formales. En el fondo, este cambio persigue también la finalidad de ahorrar costos logísticos.

Merece un comentario singular la dación del Decreto Legislativo 1492 y su Reglamento que tiene dos grandes objetivos: por un lado la digitalización de los procedimientos logísticos para el movimiento de los contenedores mediante el endose en procuración utilizando medios electrónicos; y por otro lado, la transparencia en la fijación de las tarifas por los servicios logísticos que brindan algunos operadores de comercio exterior, como las líneas navieras, Depósitos Temporales, Agentes de Carga y Agentes de Aduana.

Ojalá se apruebe pronto el Reglamento del

4. "Mesa de Partes Virtual - MPV", SUNAT, acceso el 20 de marzo de 2021, https://orientacion.sunat.gob.pe/index.php/personas-menu/centro-de-tramites-virtual/mesa-de-partes-virtual

5. Decreto Supremo $N^{\circ}$ 008-2020-MINCETUR que aprueba el Reglamento de la Ley $N^{\circ} 30860$, Ley de fortalecimiento de la Ventanilla Única de Comercio Exterior.

6. Decreto Supremo № 005-2020-MINCETUR que aprueba el Reglamento del Exportador Autorizado. 
Decreto Legislativo $1492^{7}$, para que sea implementada por las empresas vinculadas a la cadena logística internacional; dado que se trata de uno de los cambios relevantes en materia de simplificación y ahorro de costos vinculados al movimiento de contenedores dentro del territorio peruano, beneficiando de manera directa a los usuarios aduaneros que realizan operaciones de importación o exportación.

Siguiendo la misma línea de pensamiento expuesta en el párrafo anterior, se aprobó el Reglamento $\mathrm{MISLO}^{8}$, que crea el Módulo de Información sobre los Servicios de Logística de Comercio Exterior, con el propósito de brindar a los usuarios aduaneros - vale decir, importadores y exportadores-, la posibilidad de conocer con la debida antelación las tarifas o gastos que debe considerar en su planeamiento estratégico empresarial, de modo que puedan generar mayor competitividad.

\section{OPORTUNIDADES DE MEJORA}

Dentro de las iniciativas surgidas durante la pandemia, cabe mencionar que, a partir del 16 de marzo 2020, fecha en que se dispuso el aislamiento social obligatorio, los plazos y trámites que estaban pendientes por vencer tuvieron que suspenderse para no afectar los derechos del usuario aduanero y las facultades de control aduanero que ejerce la Administración Aduanera. ${ }^{9}$

Siempre van a surgir algunas oportunidades de mejora en esta etapa de confinamiento y trabajo remoto, algunas basadas por ejemplo en la digitalización de procesos, las que actualmente caminan en velocidades distintas al momento de acceder a los servicios vinculados al comer- cio exterior y los negocios internacionales. Por un lado, tenemos lo que podría llamarse la velocidad crucero a cargo de la Administración Aduanera, que le ha permitido implementar con éxito las importaciones y exportaciones digitales.

Por otro lado, tenemos un avance a velocidad moderada del parte de los operadores de comercio exterior, quienes se encuentran implementando algunas plataformas digitales o servicios electrónicos que posibiliten a sus clientes, por lo general, usuarios aduaneros, el libre acceso de manera remota a su mercancía y documentos. Consideramos que, es aquí donde surge una visible oportunidad de mejora.

El mundo ha cambiado y los servicios digitales están basados en una nueva normalidad que tiene como denominador común el e-commerce o comercio electrónico, por lo que todo servicio creado en esta etapa permanecerá incluso superada la pandemia. Dada esta situación, resistirse al cambio no aporta de manera significativa a la competitividad de los operadores de comercio exterior. Más bien, los conduce hacia una zona de riesgo, si no reaccionan a tiempo para fidelizar a sus clientes internos y externos.

En ese sentido, consideramos que se deberían emprender con mayor dinamismo planes de virtualización de procesos con el objetivo de acercarse a las necesidades del usuario aduanero, evitando en la medida de lo posible los trámites presenciales, el uso del papel impreso $y$, sobre todo, permitiendo que puedan realizar la trazabilidad en tiempo real del movimiento de sus mercancías mediante aplicativos móviles de libre acceso.

7. Nota del Editor: a la fecha de recepción del artículo, aún no se había publicado el Reglamento. Con fecha 11 de febrero del 2021, mediante el Decreto Supremo Nº01-2021-MINCETUR, se aprobó el Reglamento del Decreto Legislativo 1492.

8. Decreto Supremo N ${ }^{\circ}$ 005-2020-MINCETUR que aprueba el Reglamento del artículo 10 de la Ley N²8977 para la implementación del Módulo de Información sobre los Servicios de Logística de Comercio Exterior.

9. Informe $\mathrm{N}^{\circ} 110-2020$-SUNAT-340000. 
Cabe mencionar que existen algunos proyectos y avances que vemos con expectativa, como por ejemplo la posibilidad de generalizar el uso de los conocimientos de embarque en formatos digitales ${ }^{10}$, eliminando para siempre el requisito del endose en procuración mediante la firma y sello en el documento impreso para su validez como tal, lo cual, definitivamente aportará a la mayor competitividad de nuestro país.

\section{CONCLUSIONES}

Empezamos este artículo preguntándonos si estábamos realmente preparados para continuar realizando negocios internacionales en esa nueva normalidad. Respondemos afirmativamente indicando que han transcurrido varios meses desde que se declaró la emergencia sanitaria en el Perú, y con el transcurrir del tiempo, nos vamos adaptando a nuevas formas de gestionar los negocios internacionales, desde la comodidad de sus hogares $u$ oficinas y sin necesidad de desplazarse a las oficinas del sector público o privado.

La nueva normalidad permite que podamos realizar reuniones virtuales en diversas plataformas digitales para exponer planes estratégicos, gerenciar empresas, medir resultados, liderar equipos de alto rendimiento o concretar algunos contratos internacionales; por lo que destaca nuestra capacidad de adaptación a nuevos hábitos de convivencia social en la comunica- ción utilizando dichos medios electrónicos.

El Derecho Aduanero como disciplina jurídica autónoma se encuentra en constante cambio, no sólo por los avances de la ciencia y la tecnología que nos enfrentan a un entorno globalizado y más competitivo de los negocios internacionales, sino fundamentalmente por los retos que surgen a raíz de la crisis sanitaria global. Por ello, debemos estar en capacidad de responder con un marco jurídico que garantice la continuidad de las transacciones vinculadas al comercio exterior de bienes y servicios.

Tenemos el convencimiento que la pandemia ha generado un efecto positivo en la digitalización de servicios aduaneros, tanto en el sector público como en el sector privado, de modo que los usuarios del comercio exterior hoy cuentan con mayores herramientas digitales para gestionar los negocios internacionales aportando de ese modo a la eficiencia y simplificación de trámites administrativos.

Pero siempre surgirán nuevas oportunidades de mejora, basadas en la aldea digital que estamos construyendo en el Perú, y el reto consiste en seguir avanzando a la misma velocidad, incluso superada la pandemia, para hacer realidad otros proyectos más ambiciosos, como por ejemplo la creación de los Smart Ports ${ }^{11}$, empezando por el Callao, luego Paita, después Mollendo y así sucesivamente.

10. "El Conocimiento de Embarque Electrónico, sus antecedentes y proyecciones", en Mundo Marítimo: Información Marítima de Latinoamérica, acceso el 20 de marzo de 2021, https://www.mundomaritimo.cl/noticias/el-conocimiento-de-embarque-electronico-sus-antecedentes-y-proyecciones

11. "APN presenta el Proyecto Smart Port que permitirá transformar el Puerto del Callao en un Puerto Inteligente", Gob.pe, acceso el 20 de marzo de 2021, https://www.gob.pe/institucion/apn/noticias/303513-apn-presenta-el-proyecto-smart-port-que-permitira-transformar-el-puerto-del-callao-en-un-puerto-inteligente 